\title{
Simulation for All-Solid State Batteries with Multi-Element Network Model
}

\author{
Ryusei HIRATE ${ }^{1}$, Hiroki MASHIOKA ${ }^{1}$, Shinichiro YANO ${ }^{1}$, Yoshifumi TSUGE ${ }^{1}$, and Gen INOUE ${ }^{1}$ \\ ${ }^{1}$ Department of Chemical Engineering, Faculty of Engineering, Kyushu University, 744 Motooka, Nishi-ku, Fukuoka 819-0395 \\ Japan, +81-92-802-2757, ginoue@chem-eng.kyushu-u.ac.jp
}

\begin{abstract}
In order to increase energy density and enhance safety, all-solid-sate lithium-ion batteries have been developed as a storage battery for electric vehicle (EV). Further performance improvement of all-solid-sate lithium-ion batteries requires optimization of the electrode structure. In this paper, we constructed a phase interface model focusing on the microstructure of the porous electrode, and examined the reaction of the electrode layer structure.
\end{abstract}

\section{Introduction}

Recently, all-solid-state-lithium-ion batteries have attracted attention as next-generation batteries serving as driving sources for electric vehicles (EVs) and hybrid electric vehicles (HEVs). The all-solid-state-lithium-ion battery is a lithium ion battery $(\mathrm{LiB})$ using only solid materials, and has some remarkable features. A major feature is that it achieves high safety by using nonflammable inorganic materials as the electrolyte. In addition, a bulk-type all solid battery manufactured by layering particles can introduce a large amount of electrode active material into the electrode layer because it does not require a separator, and high capacity can be expected. However, higher energy density and higher power are issues for practical utilization.

In order to overcome this problem, high capacity negative electrode active materials such as $\mathrm{Si}$ and $\mathrm{Sn}$ and high ion conductive solid electrolytes such as $\mathrm{Li}_{10} \mathrm{GeP}_{2} \mathrm{~S}_{12}$ (LGPS) have been developed (Kamaya et al., 2011; Su et al., 2014). On the other hand, faster battery charging and discharging (i.e., high-rate performance) is becoming viewed as important. In order to improve the performance in both power density and energy density of LiBs, one solution is the optimization of electrodes layer structure which provides effective ion and electron transport during maintaining a high energy density (Inoue and Kawase, 2017). In the current LiBs, $\mathrm{Li}$ ion and electron transport in the electrode layers has been identified as the ratelimiting process during operation at high charging and discharging rates, which results in a high internal resistance (Vlad et al., 2015). One the other hand, as shown in Figure 1, since the voltage loss caused by mass transport in the porous electrode layer depends not only on the ion conductivity of the electrolyte but also on its porous structure, it is important to optimize an electrode structure as well as material characteristics such as active materials and electrolytes.
Although the majority of electrodes is designed by trial and error lately, as that monitoring the state in electrode layer during charge and discharge using the numerical computation is a critical measure to understand the phenomena inside cell such as ionic/electronic potential distribution and lithium concentration distribution. Electrode design methods employing numerical simulations are receiving growing attention (Xue et al., 2013), not only for materials design but also to the challenge of its optimization and utilization (Ikeshita et al., 2017). However, current simulations usually employ the empirical overall characteristics such as the reactive interface area and the tortuosity factor, so the phenomena resulting from minute structure of electrode layer which notably affect the cell performance might be overestimated.

Therefore, in this study, we focused on developing a numerical computation technique which reflects the local characteristics of electrode structure directly. By simulating the electrochemical reaction and mass transport phenomena in battery with this model, the effects of SE volume fraction and particle size distribution on discharge performance were verified.

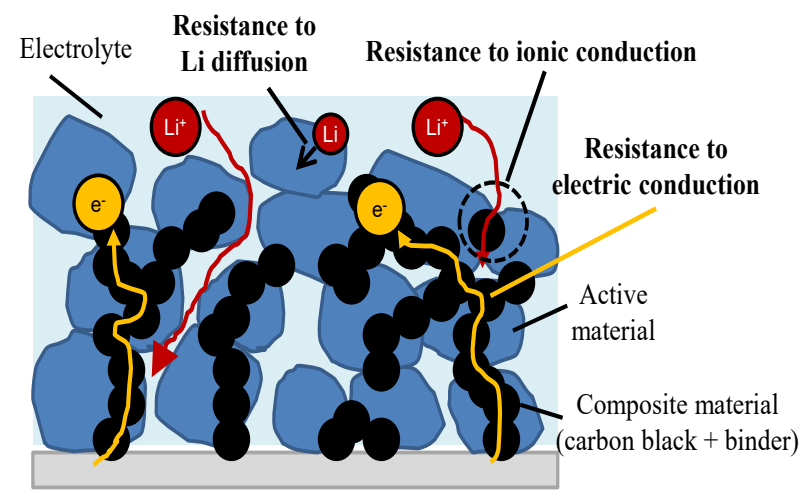

Figure 1. Mass transport in electrode layer. 


\section{Calculation Model and Structures}

The followings were assumed for the simulation carried out herein:

(1) The simulated electrode is set to contain active material and electrolyte. The active material particles are all spherical;

(2) Aggregation does not exist, so all active material exists as primary particle;

(3) The temperature distribution inside the cell is uniform;

(4) The active materials of the cathode and anode are $\mathrm{LiCoO}_{2}$ and graphite, respectively. Regardless of state of charge (SOC), the material parameters employed in the calculations are constant;

(5) LGPS was used as the electrolyte. Assuming that the inside of the electrode layer is not in a sufficient contact condition, the ionic conductivity is set to $1.2 \mathrm{mS} / \mathrm{cm}(1 / 10$ of the literature value) (Kamaya et al., 2011) ;

(6) The transport number of solid electrolyte is 1 and the concentration distribution in the electrolyte is uniform;

(7) The electron conduction path in regards to carbon black exists between active material particles;

First, active materials were located randomly in threedimensional space in this simulation. Next, electrolyte spheres with greatest diameter were located between active material particles. These electrolyte spheres represent electrolyte over the space by defining electrolyte information such as ion electric potential. After constructing an electrode structure, the active material particle network and electrolyte network were built as shown in Figure 2.

By building the Multi-Element Network, the electronic conduction can be calculated in active material network, as the ionic conduction and diffusion were calculated with electrolyte network, while the electrode reaction occurring at interface between active material particles and electrolyte can be calculated.

Based on the porous electrode theory, the reaction and mass transport phenomena at galvanostatic discharge was simulated. Table 1 shows the basic electrochemical equations employed (Doyle et al., 1993; Goldin et al., 2012; Lundgren et al., 2015), where $\varepsilon_{\mathrm{AM}}$ is the volume fraction of the active material $[-], C_{\mathrm{Li}}$ is the intercalated lithium concentration $\left[\mathrm{kmol} / \mathrm{m}^{3}\right], D_{\text {ed }}^{\text {eff }}$ is the effective diffusivity of lithium in the active material $\left[\mathrm{m}^{2} / \mathrm{s}\right], A_{\mathrm{s}}$ is the specific electrode surface area $\left[\mathrm{m}^{2} / \mathrm{m}^{3}\right], i$ is the Faradaic current density $\left[\mathrm{A} / \mathrm{m}^{2}\right], F$ is the Faraday constant $[\mathrm{C} / \mathrm{kmol}], \phi_{\text {ed }}$ is the electric potential in electrode active material particles [V], $\sigma_{\text {ed }}^{\text {eff }}$ is the effective electronic conductivity $[\mathrm{S} / \mathrm{m}], \quad \varepsilon_{\mathrm{EL}}$ is the volume fraction of the electrolyte [-], $D_{\mathrm{EL}}^{\mathrm{eff}}$ is the effective diffusivity of lithium ions in the electrolyte $\left[\mathrm{m}^{2} / \mathrm{s}\right], C_{\mathrm{Li}^{+}}$ is the lithium ion concentration in the electrolyte $\left[\mathrm{kmol} / \mathrm{m}^{3}\right], t_{\mathrm{Li}^{+}}$is the lithium ion transference number [-], $\kappa^{\text {eff }}$ is the effective ionic conductivity $[\mathrm{S} / \mathrm{m}], \phi_{\mathrm{el}}$ is the electric potential in the electrolyte $[\mathrm{V}], i_{0}$ is the exchange current density $\left[\mathrm{A} / \mathrm{m}^{2}\right], R$ is the universal gas constant $[\mathrm{J} /(\mathrm{kmol} \cdot \mathrm{K})], \eta$ is the overpotential $[\mathrm{V}], \alpha_{\mathrm{a}}$ and $\alpha_{\mathrm{c}}$ are the anodic and cathodic symmetry factors [-], $k_{\mathrm{r}}$ is a constant $\left[\mathrm{mol}^{2.5} \mathrm{kmol}^{-0.5} \mathrm{~s}^{-1}\right], E_{\mathrm{ed}}^{\mathrm{eq}}$ is the equilibrium electric potential difference [V], $X_{\text {ed }}$ is the intercalation

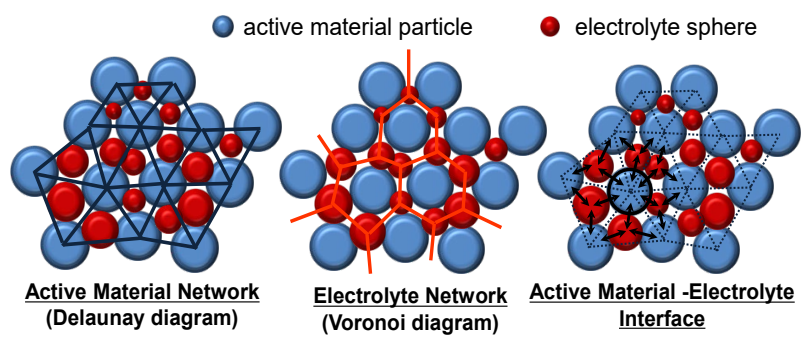

Figure 2. Schematic of Multi-Element Network.

Table 1. Basic electrochemical equations

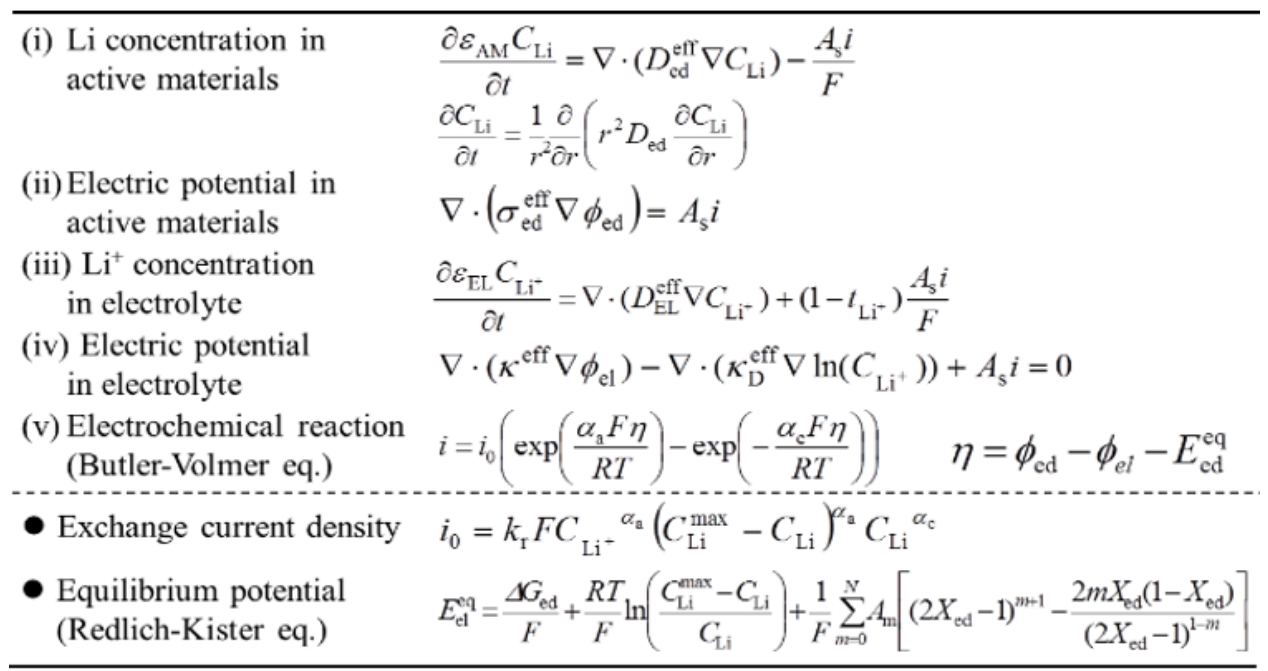


fraction at the electrode active material particle surface [-] calculated as $X_{\text {ed }}=C_{\mathrm{Li}} / C_{\mathrm{Li}}^{\max }, \sigma_{\mathrm{AM}}$ is the electronic conductivity of the active material $[\mathrm{S} / \mathrm{m}]$, and $\sigma_{\mathrm{CM}}$ is the electronic conductivity of the composite material $[\mathrm{S} / \mathrm{m}]$. Also, the boundary condition is shown in Figure 3.

In this study, we extended the basic electrochemical equations to apply to the Multi-Element Network Model. For example, instead of using the effective diffusivity of lithium ions $D_{\mathrm{EL}}^{\text {eff }}$ and the effective ionic conductivity $\kappa^{\text {eff }}$ in the electrolyte, we used original diffusivity of lithium ions in the electrolyte $D_{\mathrm{EL}}$ and ionic conductivity $\kappa$. By calculating the local connection area between pore spheres geometrically as shown in Figure 4(a), the effective diffusion or conduction flow was calculated as the product of local connection area and the diffusion/conduction flux. In the same way, the reaction rate was estimated by the Faradaic current density and the reactive surface area as shown in Figure 4(b).

The area capacity is $1.4 \mathrm{mAh} / \mathrm{cm}^{2}$, the SE layer thickness is $20 \mu \mathrm{m}$ as a common condition. The particle size distribution conditions of the active material are Case 1(Uniform particle size), Case 2(Particle size standard deviation: $1.3 \mu \mathrm{m}$ ) and Case 3(Particle size standard deviation : $5.2 \mu \mathrm{m})$. In each cases, the structure of 7 conditions of SE volume ratio difference (thickness difference) was targeted. It is the structure of $32 \mu \mathrm{m}$ (SE volume ratio $\left.\left(V_{\mathrm{SE}}=0.75\right)\right), 40 \mu \mathrm{m}(0.6), 60 \mu \mathrm{m}(0.4), 80$ $\mu \mathrm{m}(0.3), 120 \mu \mathrm{m}(0.2), 160 \mu \mathrm{m}(0.15)$, and $240 \mu \mathrm{m}(0.1)$ thick electrode.

The three conditions of $32 \mu \mathrm{m}, 60 \mu \mathrm{m}$, and $240 \mu \mathrm{m}$ thickness for each cases are shown in Figure 5 as an example. The electrode material parameters are shown in Table 2 (Goldin et al., 2012). By using above equations, input parameters and assumptions, each structure was simulated at a constant discharge rate of $1 \mathrm{C}, 5 \mathrm{C}$ and 10 C. From simulation results, discharge properties of each structure were estimated.

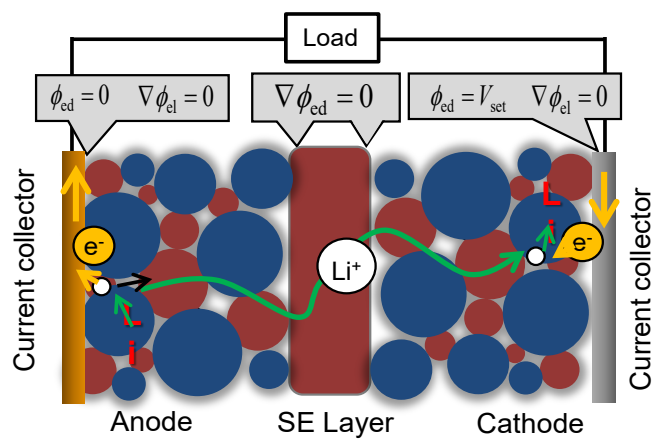

Figure 3. Schematic representation of the boundary conditions.

active material particle electrolyte sphere

a)
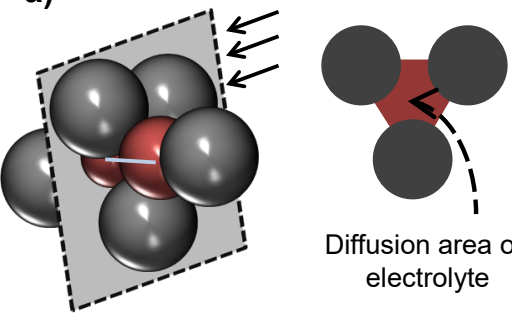

Diffusion area of electrolyte

Effective diffusion $\Rightarrow$ Electrolyte Network

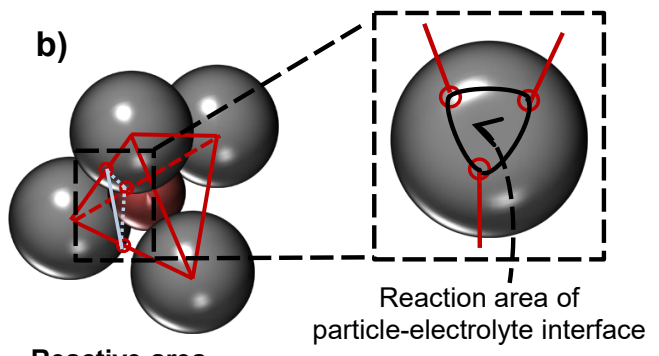

Reactive area

$\Rightarrow$ Active Material -Electrolyte Interface

Figure 4. Schematic of definition of the transport and reaction parameter

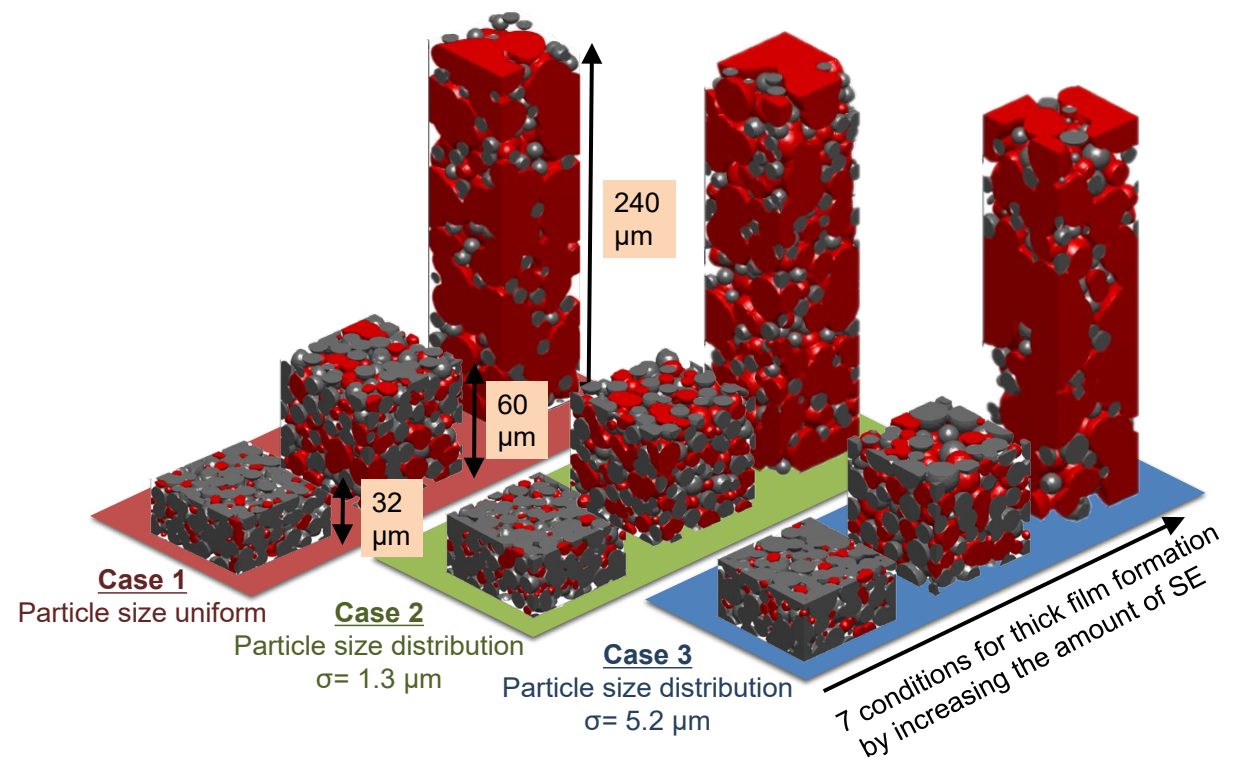

Figure 5. 3D electrode layer structures of each cases. 
Table 2. Electrode material parameters

\begin{tabular}{cccc}
\hline \multicolumn{2}{c}{ Parameter } & Anode & Cathode \\
\hline$D_{\text {ed }}$ & {$\left[\mathrm{m}^{2} / \mathrm{s}\right]$} & $1.0 \times 10^{-14}$ & $1.0 \times 10^{-14}$ \\
$\sigma_{\mathrm{AM}}$ & {$[\mathrm{S} / \mathrm{m}]$} & 100 & 10 \\
$\sigma_{\mathrm{CM}}$ & {$[\mathrm{S} / \mathrm{m}]$} & - & 368 \\
$C_{\mathrm{Li}}^{\max }$ & {$\left[\mathrm{kmol} / \mathrm{m}^{3}\right]$} & 30.94 & 52.0 \\
$C_{\mathrm{Li}}^{0 \%}$ & {$\left[\mathrm{kmol} / \mathrm{m}^{3}\right]$} & 24.73 & 50.7 \\
$C_{\mathrm{Li}}^{100 \%}$ & {$\left[\mathrm{kmol} / \mathrm{m}^{3}\right]$} & 0.031 & 20.6 \\
$T$ & {$[\mathrm{~K}]$} & 298.15 & 298.15 \\
$\alpha_{\mathrm{c}}$ & {$[-]$} & 0.5 & 0.5 \\
$\alpha_{\mathrm{a}}$ & {$[-]$} & 0.5 & 0.5 \\
$k_{\mathrm{r}}$ & {$\left[\mathrm{m}^{2.5}\right.$} & $4.52 \times 10^{-8}$ & $2.07 \times 10^{-8}$ \\
\hline
\end{tabular}

\section{Results and Discussion}

\subsection{Influence of SE amount (electrode thickness)}

In order to compare the influence of discharge performance by electrode thickness and SE volume ratio, only Case 1 is examined first. The upper figure in Figure 6 shows the galvanostatic charge curve obtained from the simulation carried out at charge rates of $1 \mathrm{C}$ and $10 \mathrm{C}$. The lower figure of it shows an enlargement of the terminal stage of discharge at $10 \mathrm{C}$. The C-rate was defined based on the cathode capacity, and the cut-off voltage was set at $3.0 \mathrm{~V}$. The horizontal axis of discharge curve graph indicates Depth of Discharge (DOD) which was calculated as follows:

$$
\mathrm{DOD}=\frac{C_{\mathrm{Li}}^{100 \%}-\bar{C}_{\mathrm{Li}}}{C_{\mathrm{Li}}^{100 \%}-C_{\mathrm{Li}}^{0 \%}}
$$

where $\bar{C}_{\mathrm{Li}}$ is the average intercalated lithium concentration in electrode, $C_{\mathrm{Li}}^{100 \%}$ and $C_{\mathrm{Li}}^{0 \%}$ are the average intercalated lithium concentration at initial state and termination. As shown in Figure 6, it can be seen that the discharge performance is almost the same at $1 \mathrm{C}$, but at a high rate of $10 \mathrm{C}$, a large difference appears. The discharge rate was improved by increasing the film thickness (increasing SE volume ratio), and it became maximum at a thickness of $160 \mu \mathrm{m}$ at $10 \mathrm{C}$. Also, the $\mathrm{Li}$ concentration on the surface of the positive electrode active material at this time is shown in Figure 7. Although the concentration is relatively uniform throughout the electrode layer at a thickness of $160 \mu \mathrm{m}$, it can be seen that the concentration of $\mathrm{Li}$ is low in the vicinity of the current collector foil for an electrode of $32 \mu \mathrm{m}$ thickness.
Similarly, even at a thickness of $240 \mu \mathrm{m}$, the $\mathrm{Li}$ concentration near the foil is low.

The effective ion conductivity in the porous media is shown in eq. (2), the relationship between SE volume ratio and thickness is shown in eq. (3), and the ion conduction conductance is linearly approximated to apply eq. (2) and eq. (3) shown in eq. (4)

$$
\begin{gathered}
\kappa^{\mathrm{eff}}=\kappa_{\mathrm{SE}}^{\mathrm{bulk}} \varphi_{\mathrm{SE}}^{\gamma} \\
L=f /\left(1-\varphi_{\mathrm{SE}}\right) \\
\frac{1}{R_{\mathrm{SE}}}=\frac{A \kappa^{\mathrm{eff}}}{L}=\frac{A \kappa_{\mathrm{SE}}^{\text {bulk }}}{f} \varphi_{\mathrm{SE}}^{\gamma}\left(1-\varphi_{\mathrm{SE}}\right)
\end{gathered}
$$

In this calculation, since the active material volumes are fixed, all reaction resistances are equal. It can be seen from eq. (4) that the ion conduction conductance has a maximum value with respect to the SE volume fraction. That is, it can be said that the effective conductivity decreases with a low SE amount, and the conduction distance increases with a high SE amount, and the result is as described above.
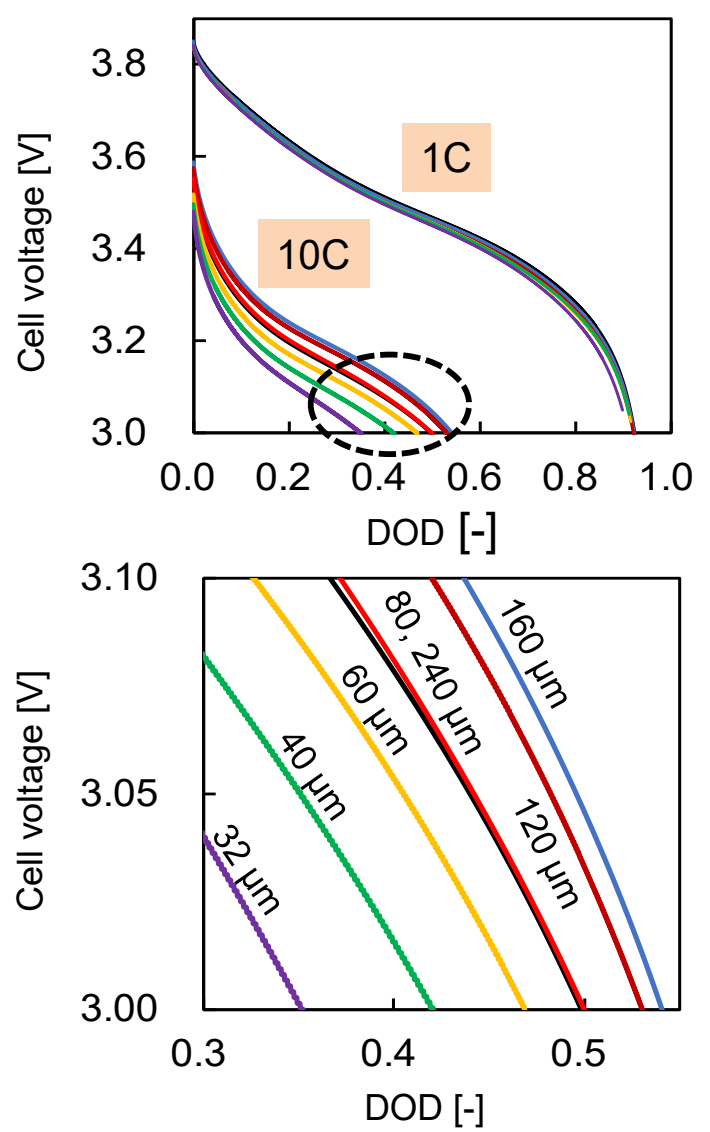

Figure 6. Relationship between discharge rate and cell voltage at $10 \mathrm{C}$ and $1 \mathrm{C}$ in Case 1 


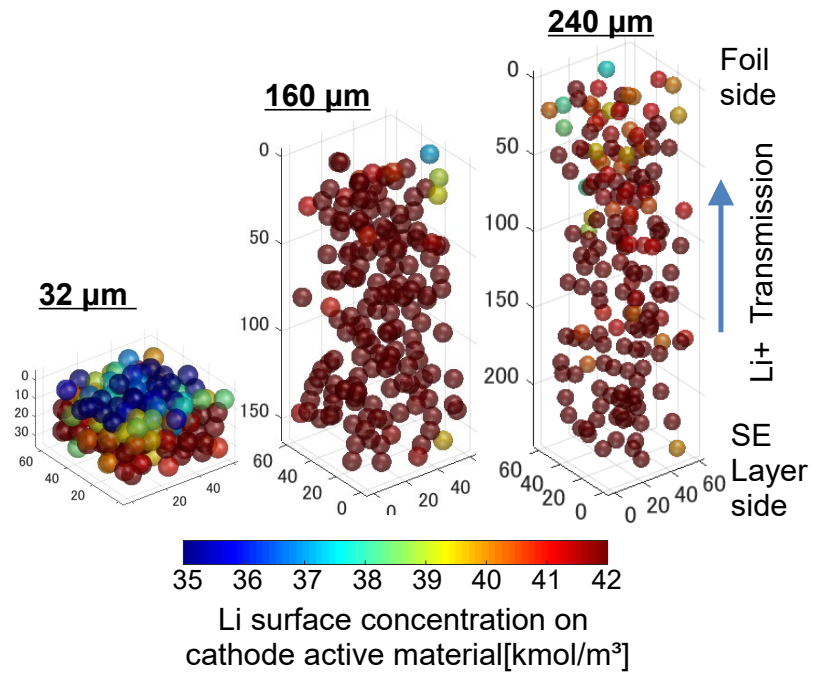

Figure 7. Surface concentration distribution of positive electrode active material at the end of $10 \mathrm{C}$ discharge

\subsection{Influence of particle size distribution}

The influence of particle size distribution is examined. Case 1 has a uniform particle size, Case 2 has a particle size distribution with a standard deviation of $1.3 \mu \mathrm{m}$, and Case 3 has a particle size distribution with a standard deviation of $5.2 \mu \mathrm{m}$. Figure 8 shows the discharge curve of $10 \mathrm{C}$ and the active material surface Li concentration at the $32 \mu \mathrm{m}$-thick electrode in each cases. The optimum electrode thickness differs depending on the particle size distribution, and the electrode thickness is $160 \mu \mathrm{m}$ in Case $1,80 \mu \mathrm{m}$ in Case 2 and $120 \mu \mathrm{m}$ in Case 3. The Case 2 has the highest discharge rate overall, and Case 2 has a thickness of $32 \mu \mathrm{m}$. The depth of discharge was improved 1.28 times more than that. When the active material surface Li concentration in the $32 \mu \mathrm{m}$ thick electrode is compared, in Case 1, the vicinity of the foil is not used, but in Case 2 having a particle size distribution, it is improved and relatively uniform. However, in Case 3 where the particle size distribution is large, the concentration of large particles is lowered, and the concentration is dispersed in the entire electrode layer.

Also, Figure 9 shows the relationship between the number of SE phase connections in each case, and Figure 10 shows the change in central concentration in each particle of Case 2 and Case 3. From Figure 9, it is possible to confirm an increase in the number of connection points between SEs by giving the particle size distribution. Therefore, the particle size distribution can be said to be advantageous in terms of ion conductivity, but looking at Figure 10, the concentration of large particles in Case 3 does not change, leading to an increase in intraparticle diffusion resistance, which leads to a decrease in capacity. From the above, it was found that the optimum particle size distribution exists in terms of ion conduction and particle utilization.
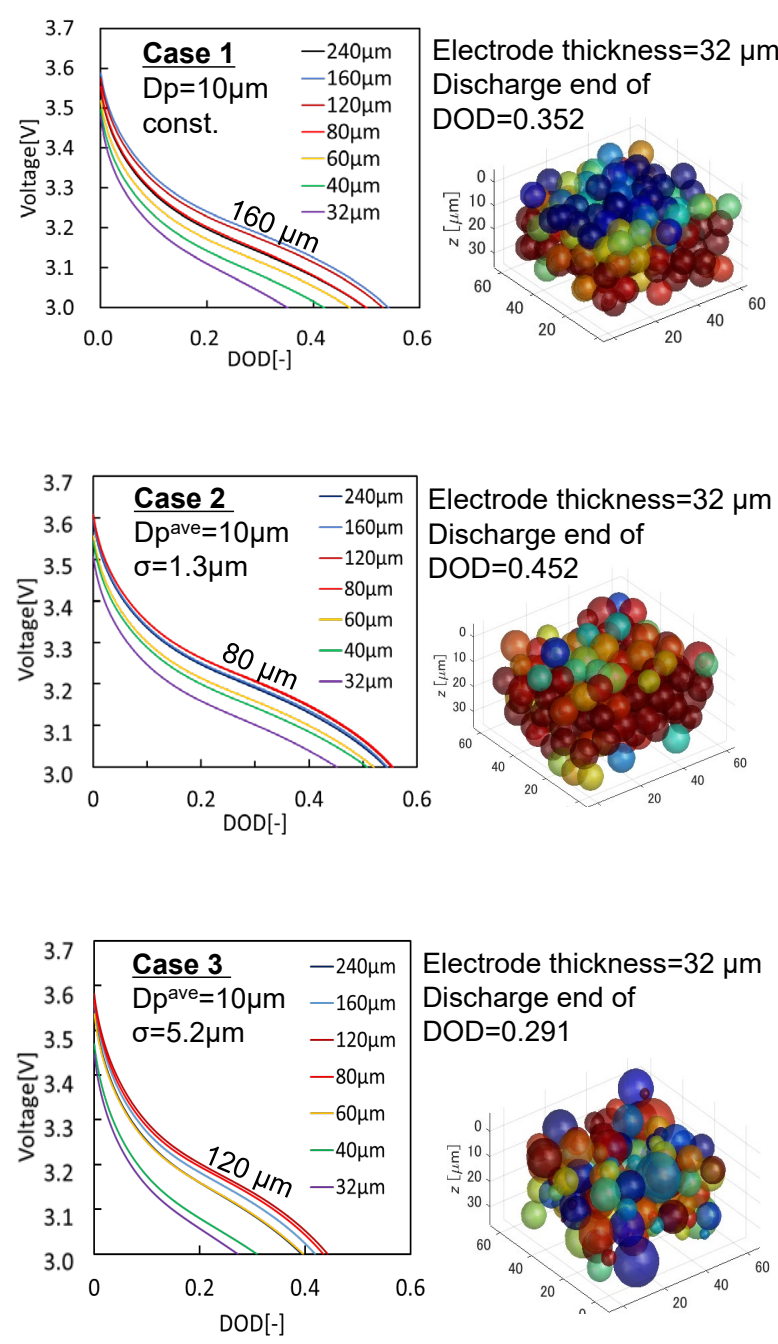

Figure 8. Discharge curve of $10 \mathrm{C}$ in each case and distribution of Li concentration on active material surface at 32 $\mu \mathrm{m}$ thickness electrode

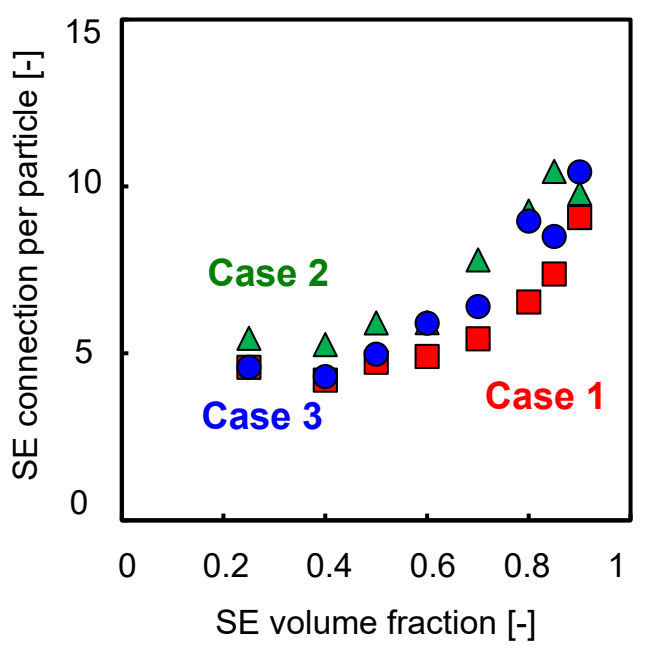

Figure 9. SE phase connection in each structure 


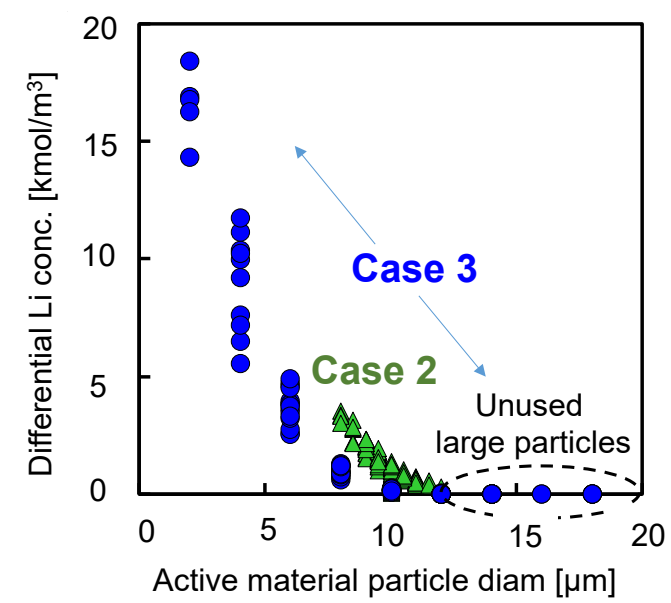

Figure 10. Central Li concentration of each particle of Case 2 and Case 3 at the end of $10 \mathrm{C}$ discharge

\section{Conclusion}

For the optimization of electrode layers, we investigated the effects of the structure conditions on discharge property using numerical simulations that consider the minute structure in electrode layer. As the SE content increased, the ion conductivity improved and the effective capacity improved. However, an excessive increase in the amount of SE causes a decrease in capacity due to an increase in the conduction distance. In addition, although a suitable active material particle size distribution is effective for improving the connectivity of the SE phase, an excessive distribution leads to an increase in intraparticle $\mathrm{Li}$ diffusion resistance. These results therefore indicated the importance of porous structure condition in electrode design, and implied the utility of this calculation model.

\section{References}

Doyle, M., T. F. Fuller, and J. Newman; "Modeling of Galvanostatic Charge and Discharge of the Lithium/Polymer/Insertion Cell," J. Electrochem. Soc, 140, 1526-1533 (1993)

Goldin, G. M., A. M. Colclasure, A. H. Wiedemann, and R. J. Kee; "Three-dimensional Particle-resolved Models of Li-ion Batteries to Assist the Evaluation of Empirical Parameters in One-dimensional Models,"Electrochim. Acta, 64, 118-129 (2012)

Ikeshita, K., G. Inoue, and M. Kawase; "Electrode Designs of Lithium Ion Batteries Utilizing the Simulation of Porous Structures," ECS Transactions, 75(20) 165-172 (2017)

Inoue, G. and M. Kawase; "Numerical and Experimental Evaluation of the Relationship between Porous Electrode Structure and Effective Conductivity of Ions and Electrons in Lithium-ion Batteries," $J$. Power Sources, 342, 476-488 (2017)
Kamaya, N., K. Homma, Y. Yamakawa, M. Hirayama, R. Kanno, M. Yonemura, T. Kamiyama, Y. Kato, S. Hama, K. Kawamoto, and A. Mitsui; "A Lithium Superionic Conductor," Nat. Mater, 10, 682-686 (2011)

Lundgren, H., M. Behm and G. Lindbergh;

"Electrochemical Characterization and Temperature Dependency of Mass-Transport Properties of LiPF6 in EC:DEC," J. Electrochem. Soc, 162 (3), A413A420 (2015)

Su, X., Q. Wu, J. Li, X. Xiao, A. Lott, W. Lu, B. W. Sheldon, and J. Wu; "Silicon - Based Nanomaterials for Lithium - Ion Batteries," $A d v$. Energy Mater, 4, 1300882 (2014)

Vlad, A., N. Singh, C. Galande, and P.M. Ajayan; "Design Considerations for Unconventional Electrochemical Energy Storage Architectures," Adv. Energy Mater, 5, 1402115 (2015)

Xue, N., W. Du, A. Gupta, W. Shyy, A. M. Sastry, and J. R. R. A. Martins; "Optimization of a Single Lithium-Ion Battery Cell with a Gradient-Based Algorithm," J. Electrochem. Soc, 160(8), A1071A1078 (2013) 